\title{
GEOTECNOLOGIAS COM APOIO DE INDICES MORFOMÉTRICOS PARA A CARACTERIZAÇÃO DA BACIA HIDROGRÁFICA DO RIO PEIXE-BOI, NORDESTE PARAENSE
}

Bruno Wendell de Freitas Pereira ${ }^{1}$, Maria de Nazaré Martins Maciel², Francisco de Assis de Oliveira ${ }^{3}$, Bruno Monteiro Ferreira ${ }^{4}$, Ellen Gabriele Pinto Ribeiro ${ }^{4}$

1 Professor Mestre do Instituto Ciberespacial da Universidade Federal Rural da Amazônia

(brunowendell@yahoo.com.br) Belém-Pará

2 Professora Doutora do Instituto Ciberespacial da Universidade Federal Rural da Amazônia

3 Professor Doutor do Instituto de Ciências Agrarias da Universidade Federal Rural da Amazônia

4 Engenheiros Florestais do Instituto Ciberespacial da Universidade Federal Rural da Amazônia

Recebido em: 08/09/2015 - Aprovado em: 14/11/2015 - Publicado em: 01/12/2015 DOI: http://dx.doi.org/10.18677/Enciclopedia_Biosfera_2015_165

Diante das questões que englobam escassez e gerenciamento dos recursos hídricos, esse artigo tem como objetivo gerar um modelo de representação gráfica da bacia hidrográfica do rio Peixe-Boi, nordeste paraense, assim como a extração da rede de drenagem e ordem dos rios. Para isso, utilizou-se técnicas de geoprocessamento e dados de Modelo Digital de Elevação (MDE) do Shuttle Radar Topography Mission (SRTM), obtidas no banco de dados TOPODATA do Instituto Nacional de Pesquisas Espaciais (INPE) e caracterização morfométrica. A análise e delimitação da bacia hidrográfica e da rede de drenagem foram obtidas através de ferramentas do software ArcGis 10.1, (módulo Hidrology). Com os resultados obtidos verificou-se que a bacia apresentou drenagem de $1.034 \mathrm{~km}^{2}$ e o perímetro de 219,15 $\mathrm{km}$, sendo caracterizada como uma bacia de grande porte. Apresentou um formato alongado e que juntamente com a avaliação de índices de relevo e hidrografia, mostrou-se pouco favorável a inundações, sendo classificada como de $4^{\underline{a}}$ ordem. A bacia apresenta uma baixa densidade de drenagem, elevada permeabilidade do solo e pequena densidade hidrográfica, apresentando canais pouco sinuosos e com pequena declividade e bifurcação, e no que tange a hierarquia fluvial. Desse modo, espera-se que este estudo sobre as dinâmicas dos processos hidrogeomorfológicos possa contribuir para o manejo racional do uso da terra na bacia hidrográfica do rio Peixe-Boi, visando dar subsídios às diretrizes básicas de ações ambientais sustentáveis.

PALAVRAS-CHAVE: rede de drenagem, sistemas de informação geográfica, gerenciamento hídrico 


\title{
GEOTECHNOLOGIES WITH SUPPORT OF INDICES OF MORPHOMETRIC CHARACTERIZATION OF BASIN OF MANATEE RIVER, NORTHEAST PARAENSE
}

\begin{abstract}
The issues that include shortages and management of water resources, this article aims to generate an imaging model of river basin Manatee, northeastern Pará, as well as the extraction of drainage network and order rivers. For this, we used techniques of GIS and Digital Elevation Model data (MDE) from Shuttle Radar Topography Mission (SRTM) obtained in TOPODATA database of the National Institute for Space Research (INPE) and morphometric characterization. The analysis and definition of the catchment and drainage system were obtained by software tools ArcGIS 10.1, (Hidrology module). With the results obtained it was found that the basin drain presented 1,034 square kilometers and $219.15 \mathrm{~km}$ perimeter, is characterized as a large bowl. Presented an elongated shape and which together with the evaluation of topography and hydrography rates, proved unfavorable to flooding, being ranked 4th order. The basin has a low drainage density, high permeability soil and small river density, with little winding canals and small slope and fork, and when it comes to river hierarchy. Thus, it is expected that this study on the dynamics of hidrogeomorfológicos processes can contribute to the rational management of land use in the catchment area of the river Manatee, aiming to provide subsidies to the basic guidelines of sustainable environmental actions.
\end{abstract}

KEYWORDS: drainage network, geographic information systems, water management

\section{INTRODUÇÃO}

O estudo das redes hidrográficas, coloca-se na atualidade entre os setores mais dinâmicos no que se refere a avaliações de impactos da ação humana ao meio ambiente. Dessa forma, as bacias constituem-se em uma relevante unidade de área para o estudo e planejamento integrado dos recursos naturais.

Segundo a Secretaria do Meio Ambiente - SEMA do Estado do Pará (2012), embasada pela Lei estadual № 6.381 e Lei federal № 9.433, os recursos hídricos de uma bacia hidrográfica são considerados unidades de planejamento e gestão, onde devem ser definidos seus limites e perímetro, para ao diagnóstico dos principais problemas, potencialidade ou necessidades que possibilitem um melhor conhecimento da real situação dos recursos hídricos.

MACHADO et al. (2011), afirmam que quando se analisa uma bacia hidrográfica deve-se fazer comparações entre dados hídricos para determinar os valores de hidrologia, de maneira indireta. Neste sentido, a análise morfométrica aplicada em bacias hidrográficas é definida como vários procedimentos metodológicos que tem como orientação, a investigação e a compreensão cientifica dos componentes naturais de uma determinada bacia hidrográfica.

No apoio às ações de pesquisa, planejamento e de gestão de recursos hídricos, as geotecnologias definidas como o conjunto de tecnologias para a coleta, processamento, análise e oferta de informação com referência geográfica, e os resultados de sensoriamento remoto e de sistemas de informação geográfica (SIG), têm sido amplamente utilizadas e recomendadas (LANG \& BLASCHKE, 2009).

Entre os dados de sensoriamento remoto que podem ser muito utilizados para o trabalho em bacias hidrográficas, estão os do Shuttle Radar Topography Mission (SRTM). Esses dados abrangem mais de $83 \%$ do globo terrestre e referem- 
se aos dados de altimetria, cujos locais onde os dados espaciais são escassos, os mesmos têm auxiliado em estudos do relevo e recursos hídricos.

No contexto da necessidade de correlação de diversas variáveis ambientais, o SIG mostra-se importante na agilidade de geração de informações e na síntese dos dados, bem como na representação cartográfica das informações geradas.

Desta forma, o objetivo deste trabalho consiste em utilizar a geotecnologia, com ênfase nos produtos de sensoriamento remoto e técnicas de geoprocessamento para realizar uma análise dos parâmetros morfométricos do relevo e da drenagem da bacia hidrográfica do rio Peixe-Boi, no nordeste do estado do Pará. Para isso será elaborado um modelo de representação da bacia, em questão, e da confecção de mapas temáticos, visando com isso dar subsídios às diretrizes básicas de ações ambientais sustentáveis.

\section{MATERIAL E MÉTODOS}

\section{Caracterização da área de estudo}

A bacia hidrográfica alvo de estudo está localizada na mesorregião do Nordeste Paraense, mais precisamente na microrregião denominada Bragantina. Estende-se entre as coordenadas $0^{\circ} 53^{\prime} 57^{\prime \prime} \mathrm{S}$ e $1^{\circ} 26^{\prime} 10^{\prime \prime} \mathrm{S}$ de Latitude e $47^{\circ} 24^{\prime}$ 29" W e 47 7' 24" W de Longitude. Esta bacia tem c omo rio principal o rio Peixe-Boi, com cerca de $60 \mathrm{Km}$ de extensão, sendo sua nascente está situada próxima à localidade de Santo Antônio de Cumaru, enquanto sua foz ocorre no Rio Maracanã, do qual é tributário.

Sua área abrange um total de seis municípios: Bonito, Capanema, Nova Timboteua, Peixe-Boi, Primavera e Santarém Novo (Figura 1). Em estudos anteriores CRUZ et al., (2009), constataram que a bacia mostra-se inadequada para a geração de energia elétrica e para navegação de grandes embarcações em função do seu baixo calado.

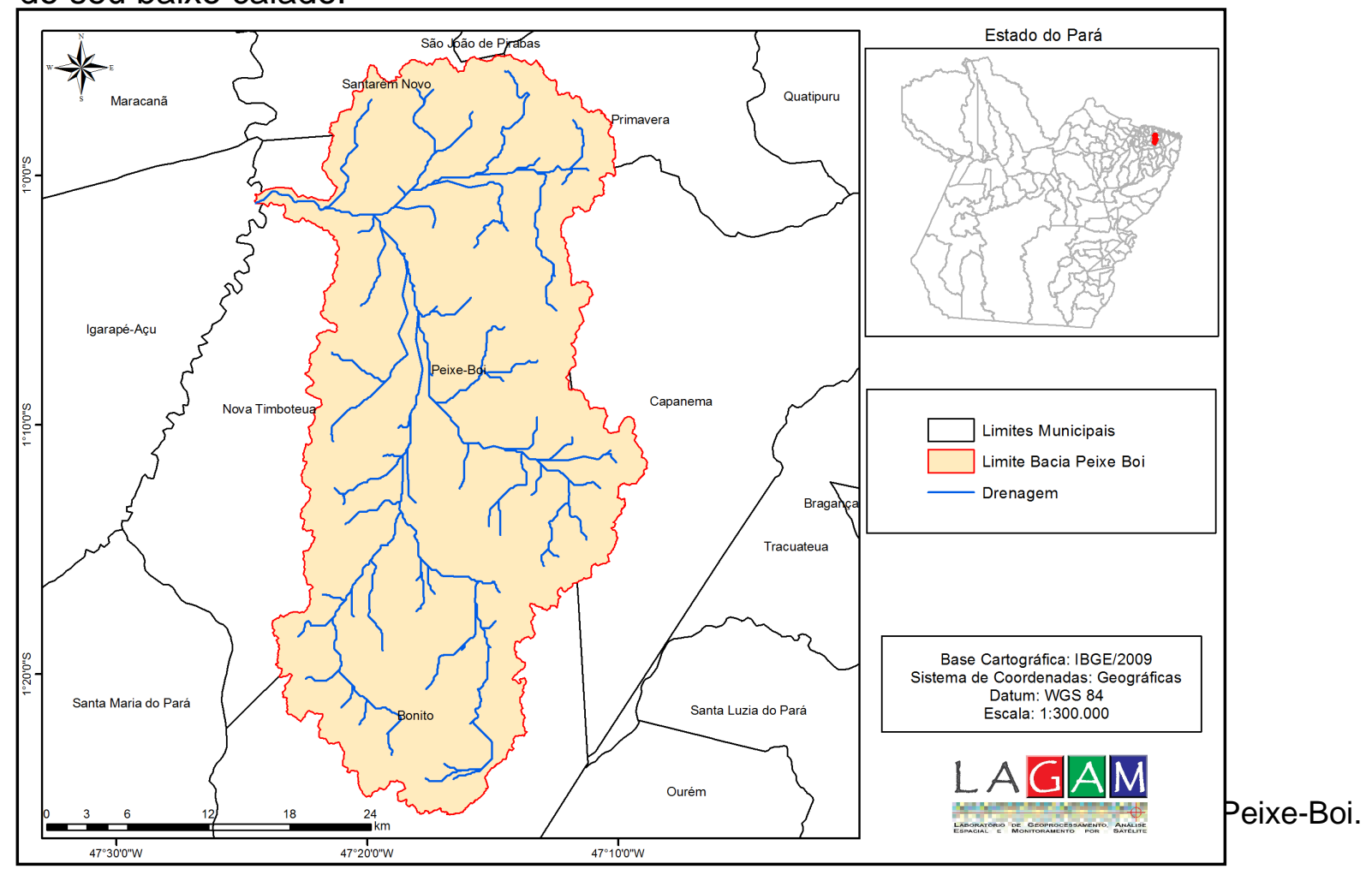


A região apresenta o clima do tipo $\mathrm{Am}$, de acordo com a classificação de Köppen. A precipitação pluviométrica média é por volta $2.200 \mathrm{~mm}$ anuais. A temperatura varia entre 29 e $31^{\circ} \mathrm{C}$, sendo que a temperatura média fica por volta de $26 \stackrel{\circ}{\circ}$. Também apresenta elevada umidade, oscilando em torno de 75 a $92 \%$. O relevo apresenta formas suaves de tabuleiros e elevações ligeiramente colinoformes, além de planaltos e planícies fluviais, e sua constituição geológica inserida no Terciário da Formação Barreiras e sedimentos do Quaternário Atual e Subatual (IBGE, 2008).

Os solos que abrangem a área da bacia do rio Peixe Boi são representados pelos Latossolo Vermelho Amarelo Distrófico Típico, com estrutura média de nível plano e suavemente ondulado tendo ainda a presença de Plintossolo Petrico Concrecionário Argissolico ( $F F c$ ), são encontrados também em alguns municípios que fazem parte da bacia o Gleissolo Háplico Eutrófico Tipico, muito Argiloso e estrutura plana (IBGE, 2012).

A cobertura vegetal primitiva de Floresta Densa de Terra Firme foi quase que totalmente substituída por vegetação secundária em vários estágios de sucessão, pela ação dos desmatamentos demandados para a implantação do sistema produtivo, representado pelo plantio de espécies agrícolas de subsistência e principalmente por pastagens cultivadas, destinados à pecuária de leite e de corte. Restam relativamente íntegras, ainda, alguns trechos de florestas ripárias, representadas pelas matas de várzea e de igapó, que ocupam as margens dos rios e outros trechos sob influência da inundação periódica dos mesmos. Segundo estudos de SILVA \& LIMA (2000), as espécies de árvores mais encontradas na vegetação florestal presente na região da bacia do rio Peixe-Boi são: Eschweilera coriácea (Matamatá-preto), Lecythis idatimon (Matamatá), Rinorea neglecta (Quariquarana), Protium pilosum (Breu), Trichilia rubra (Caxuá vermelho), Vismia guianensis (Lacre), Lacistema pubescens (Apuizinho), Croton matourensis (Maravuvuia), Rollinia esxucca (Envira) e Inga thibaudiana (Ingá roceiro).

\section{Materiais}

Como material inicial obtido para a realização deste trabalho foram utilizados os dados altimétricos SRTM/Topodata, com resolução espacial de 30 metros, obtidas a partir da grade vetorial no banco de dados do projeto Topodata do INPE (INPE/DPI, 2014), oriundos da interpolação por krigagem de dados SRTM. Foram utilizadas duas imagens (Cenas) do tipo Modelo Digital de Elevação (MDE) de números $00 S 48$ e 01S48, articulada às cartas na escala de 1:250.000. Para fazer o mosaico das imagens, a delimitação da bacia hidrográfica e a extração da rede de drenagem foram utilizadas ferramentas do software ArcGis 10.1, especificamente o módulo Hidrology Modeling.

Posteriormente foi necessário a reprojeção cartográfica da imagem de WGS 84 para UTM Zona 23S, a fim de parear os parâmetros dos arquivos raster. Utilizandose do módulo Spatial Analyst do software ArcGis 10.1, e com as ferramentas Hidrology foram realizados os processamentos e análises hidrológicas da bacia do rio Peixe-Boi.

\section{Procedimentos metodológicos para delimitação da bacia e extração da rede de drenagem}

Seguindo a orientação de DIAS et al., (2004), o processo de delimitação automática da bacia hidrográfica foi metodologicamente subdividido em quatro etapas, sendo: preenchimento de depressões ("fill sinks"), direção de fluxo ("flow 
direction"), fluxo acumulado ("flow accumulation") e delimitação de bacias ("Watershed").

A etapa de preenchimento de depressões é o primeiro tratamento dado à matriz de altitudes e serve para corrigir erros em dados referentes a terrenos com relevo íngreme, com inclinação acima de $20^{\circ}$, devido ao sombreamento ocasionado no radar.

$\mathrm{Na}$ etapa de direção de fluxo foi gerada uma grade regular definindo as direções de fluxo, tomando-se por base a linha de maior declividade do terreno. Essa grade numérica gerada determina a direção de maior declividade de um pixel em relação a seus oito pixels vizinhos, mostrando assim a direção que o curso d'água irá percorrer após atingir cada pixel.

Já na etapa de fluxo acumulado obtém-se grau de confluência do escoamento e pode ser associado ao fator comprimento de rampa aplicado em duas dimensões. O fluxo acumulado representa a rede hidrográfica, sendo possível montar nova grade contendo os valores de acúmulo de água em cada pixel. Desse modo, cada pixel recebe um valor correspondente ao número de pixels que contribuem para que a água chegue até ele.

Finalmente na etapa de delimitação da bacia que ocorre o delineamento da bacia por meio do processamento dos mapas de direção de fluxo e fluxo acumulado. A delimitação da bacia foi realizada a partir da entrada da direção de fluxo (Basin), onde o produto raster obtido foi transformado em arquivo do tipo shapefile pelo algoritmo Raster to polygon, resultando na forma da bacia.

\section{Procedimentos metodológicos para a caracterização morfométrica da bacia}

As relações morfométricas, a geomorfologia e o relevo propriamente ditos expressam a taxa de deflúvio, isto é, sobre o regime de produção de água, consequentemente sobre a taxa de sedimentação. O padrão de drenagem da bacia, ou seja, o caráter e extensão de seus canais vão exercer influência sobre a disponibilidade de sedimentos e a taxa de formação do deflúvio. A estrutura geológica também exerce influência e controle sobre as características físicas da bacia hidrográfica (STIPP et al., 2010).

O processo de caracterização morfométrica foi delineado a partir de parâmetros geométricos, de relevo e de drenagem da bacia hidrográfica descritos segundo TONELLO et al., (2006). A escolha dos parâmetros hidrológicos foi baseada nos trabalhos de MACHADO et al., (2011), SANTOS et al., (2012) e FERRARI et al., (2013), sendo selecionados os mais recorrentes e relevantes aos objetivos deste trabalho:

Parâmetros Geométricos: Esses parâmetros relacionam as primeiras e principais medidas da bacia.

$\rightarrow$ Área de drenagem $(A)$ e Perímetro $(P)$ : Refere-se a toda área drenada pelo conjunto do sistema fluvial e o perímetro referido para essa área, fornecidos respectivamente em $\mathrm{Km}^{2}$ e $\mathrm{Km}$. Tais parâmetros foram obtidos a partir das ferramentas de cálculo de área e perímetro, do software ArcGis 10.1.

$\rightarrow$ Comprimento do eixo: Corresponde ao comprimento horizontal ou vertical da bacia (dependente da orientação da mesma). Para a obtenção deste parâmetro foi utilizada a ferramenta mensure, do software ArcGis 10.1.

$\rightarrow$ Coeficiente de compacidade $(\mathrm{Kc})$ : Se dá pela relação entre o perímetro da bacia e a circunferência de um círculo cuja área seja igual à área de drenagem desta bacia. Para isso quando o coeficiente de compacidade for igual a 1 a bacia é circular, 
quando superior a 1 ela é alongada. Para obtenção de Kc foi utilizada a fórmula desenvolvida por Villela e Mattos (1975): Kc = 0,28 x P / $\sqrt{ } \mathbf{A}$

Onde: Kc é o coeficiente de compacidade; $\mathbf{P}$ é o perímetro $(\mathrm{Km})$; $\mathbf{A}$ é a área de drenagem $\left(\mathrm{Km}^{2}\right)$.

$\rightarrow$ Fator forma $(\mathrm{Ff})$ : Representa a relação entre a área e o comprimento axial da bacia. Foi determinado utilizando-se a seguinte equação desenvolvida por Villela e Mattos (1975): $\mathbf{F f}=\mathbf{A} / \mathbf{L}^{2}$

Onde: Ff é o fator de forma; A é a área de drenagem $\left(\mathrm{Km}^{2}\right)$; $\mathbf{L}$ é o comprimento do rio principal $(\mathrm{Km})$.

$\rightarrow$ Índice de circularidade (Ic): Refere-se a relação entre a área total da bacia e a área de um círculo de perímetro igual ao da bacia em questão. $O$ índice de circularidade tende para a unidade à medida que a bacia se aproxima da forma circular e diminui à medida que a forma se torna alongada. Para sua determinação, utilizou-se a seguinte equação desenvolvida por Christofoletti (1980):Ic = 12,57 x A / $\mathbf{P}^{2}$

Onde: Ic é o índice de circularidade; $\mathbf{A}$ é a área de drenagem $\left(\mathrm{Km}^{2}\right)$; $\mathbf{P}$ é o perímetro. Parâmetros de Relevo: As características de relevo de uma bacia têm fundamental influência sobre os fatores hidrológicos, pois a velocidade do escoamento superficial, e consequentemente o tempo de concentração, são determinados pela declividade do terreno (MOSCA, 2003). Assim, é de grande importância a determinação de curvas características do relevo de uma bacia hidrográfica.

$\rightarrow$ Altitude Máxima, Altitude Mínima e Altitude Média: Parâmetros determinados através software ArcGis 10.1, pelo módulo 3D Analyst Tools.

$\rightarrow$ Declividade Máxima, Declividade Mínima e Declividade Média: Foram obtidas através software ArcGis 10.1 após a modelagem das classes de declividade.

$\rightarrow$ Amplitude Altimétrica $(\mathrm{Hm})$ : Para a determinação deste parâmetro utiliza-se a seguinte equação proposta por Schumm (1956): Hm = Hmax - Hmin

Onde: Hm é Amplitude Altimétrica; Hmax é Altitude Máxima; Hmin é Altitude Mínima.

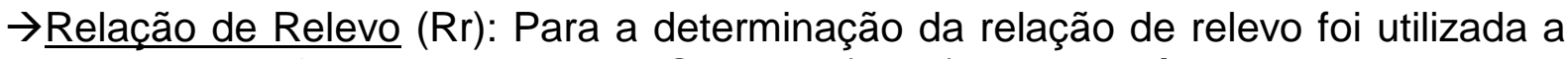
seguinte equação desenvolvida por Schumm (1956): $\mathbf{R r}=\mathbf{H m} / \mathbf{L}$

Onde: $\mathbf{R r}$ é a relação de relevo; $\mathbf{H m}$ é a amplitude altimétrica; $\mathbf{L}$ comprimento do eixo da bacia.

$\rightarrow$ Índice de Sinuosidade (Is): Este índice foi determinado através da equação desenvolvida por Schumm (1956): Is = Lt/ L

Onde: Is: é o índice de sinuosidade; Lt é o comprimento do rio principal; L é o comprimento do eixo da bacia.

$\rightarrow$ Índice de Rugosidade (Ir): Índice utilizado para análise dimensional da topografia, combinando informações pertinentes à amplitude topográfica e à densidade de drenagem: Ir = H x Dd

Onde: Ir é o índice de rugosidade; $\mathbf{H}$ é a amplitude Altimétrica; Dd é a densidade de drenagem.

$\rightarrow$ Textura Topográfica (Tt): Define o grau de entalhamento e dissecação do relevo, onde se expressa o espaçamento entre canais de drenagens em mapas topográficos com curvas de nível: $\mathrm{Tt}=1,6582462$ / $\mathbf{D d}^{1,115}$

Onde: Tt é a Textura topográfica; Dd Densidade de drenagem.

$\rightarrow$ Fator Topográfico (Ft): Relaciona os dados morfométricos das bacias hidrográficas, através de parâmetros hipsométricos e hidrológicos, para avaliar a capacidade de escoamento superficial de uma bacia (TEIXEIRA; CRUZ, 2005). É a 
relação do índice de circularidade com a densidade hidrográfica e a gradiente do relevo expresso pela razão de relevo: $\mathbf{F t}=\mathbf{D h} \mathbf{x} \mathbf{I c} \mathbf{x} \mathbf{R r}$

Onde: Ft é o fator topográfico; Dh é a densidade hidrográfica; Ic é o índice de circularidade e $\mathbf{R r}$ é a razão de relevo.

Parâmetros da Rede de Drenagem: Esses parâmetros relacionam as principais medidas da rede hidrográfica bacia.

$\rightarrow$ Comprimento do rio principal (L): É a distância da foz até a nascente mais distante da mesma. Para a obtenção do comprimento do canal principal da bacia foi utilizada a ferramenta calculate Length do software ArcGis 10.1.

$\rightarrow$ Comprimento total da rede de Drenagem ( $L t)$ : Representa a soma de toda a rede de drenagem que compõe a bacia. Para a obtenção do comprimento de todos os canais da bacia foi utilizada a ferramenta calculate Length, do software ArcGis 10.1.

$\rightarrow$ Densidade de drenagem (Dd): Correlaciona o comprimento total dos canais de escoamento e a área da bacia. A densidade da drenagem foi determinada através da equação proposta por Horton (1945): $\mathbf{D d}=\mathbf{L} / \mathbf{A}$

Onde: Dd é a densidade da drenagem; $\mathbf{L}$ é o comprimento de todos os canais; $\mathbf{A}$ é a área da bacia.

$\rightarrow$ Densidade hidrográfica (Dh): É a relação entre o número de rios e a área da bacia hidrográfica. Para CHRISTOFOLETTI (1980), a importância da densidade hidrográfica é fundamentalmente por representar o comportamento hidrográfico de uma área, assim como, a capacidade de gerar novos cursos d'água. É obtido pela formula: Dh $=$ N/A

Onde: $\mathbf{D h}$ é a densidade hidrográfica; $\mathbf{N}$ é número total de canais; $\mathbf{A}$ é a área da bacia.

$\rightarrow$ Densidade de Confluência (Dc): Representa de uma forma mais simples a densidade da drenagem de uma bacia, onde é obtida pela divisão número de bifurcações da rede de drenagem pela área da bacia segundo CHRISTOFOLETTI (1980), é dada pela expressão: $\mathbf{D c}=\mathbf{N c} / \mathbf{A}$

Onde: Dc é a densidade de confluência; $\mathbf{A}$ é a área da bacia em km²; Nc é o número de confluências da rede de drenagem.

$\rightarrow$ Relação de Bifurcação (Rb): Indica o grau de dissecação da bacia hidrográfica, quanto maior for o valor do índice de bifurcação maior será o grau de dissecação, valores geralmente abaixo de 2 indica relevo colinoso, segundo descrição de Castro e Carvalho (2009). É obtido pela formula $\mathbf{R b}=\mathbf{N w} / \mathbf{N w}+\mathbf{1}$

Onde: $\mathbf{R b}$ é a relação de bifurcação; Nw é o número de seguimentos de determinada ordem e, $\mathbf{N w + 1}$ é o número de segmentos da ordem imediatamente superior.

$\rightarrow$ Coeficiente de torrencialidade $(\mathrm{Ct})$ : Possibilita quantificar a tendência de uma bacia hidrográfica em relação à ocorrência de inundações. Esta tendência será tanto maior quanto maior for o valor deste coeficiente. É dada pela expressão $\mathbf{C t}=\mathbf{D h}$ xDd

Onde: Ct é o coeficiente de torrencialidade; Dh é a Densidade hidrográfica; Dd é a Densidade drenagem.

$\rightarrow$ Ordem da Bacia: A finalidade da ordenação dos canais é estabelecer a hierarquia fluvial que visa à classificação de determinado curso d'água no conjunto total da bacia hidrográfica na qual se encontra. De um modo geral, a ordem dos cursos d'água foi determinada através do programa ArcGis, módulo Hidrology, o qual segue os critérios introduzidos por STRAHLER (1952). 
A partir do processamento e análise dos dados de Modelo Digital de Elevação, obtidos pelos dados SRTM/TOPODATA (INPE), foi possível obter a delimitação da bacia hidrográfica do rio Peixe-Boi, assim como a modelagem de toda a rede de drenagem que compõe esta bacia.

Foi verificado que a bacia hidrográfica do rio Peixe-Boi possui uma área de $1.034 \mathrm{~km}^{2}$, abrangendo um total de seis municípios, sendo que $43,55 \%$ de sua área pertencem ao município de Peixe-Boi, 7,42\% ao município de Capanema, 5,61\% Santarém Novo, $\mathbf{1 5 , 3 9 \%}$ Nova Timboteua, $24,34 \%$ Bonito e 3,60\% ao município de Primavera. E apenas um pequeno percentual de $0,09 \%$ pertence aos municípios de São João de Pirabas e Igarapé-Açu, o que fez com que tais municípios fossem desconsiderados nas análises.

A determinação dos parâmetros morfométricos da bacia hidrográfica de estudo podem ser observados na Tabela 1.

TABELA 1: Características morfométricas obtidas para a bacia hidrográfica do rio Peixe-Boi.

\begin{tabular}{|c|c|c|c|}
\hline & CARACTERÍSTICAS FÍSICAS & UNIDADES & RESULTADOS \\
\hline \multirow{6}{*}{$\begin{array}{l}\text { Parâmetros } \\
\text { Geométricos }\end{array}$} & Área de drenagem $(\mathrm{A})$ & $\mathrm{Km}^{2}$ & 1034 \\
\hline & Perímetro $(\mathrm{P})$ & $\mathrm{Km}$ & 219,15 \\
\hline & Comprimento do eixo & $\mathrm{Km}$ & 55,07 \\
\hline & Coeficiente de compacidade $(\mathrm{Kc})$ & Adimensional & 1,9 \\
\hline & Fator forma $(\mathrm{Ff})$ & Adimensional & 0,255 \\
\hline & Índice de circularidade (Ic) & Adimensional & 0,27 \\
\hline \multirow{12}{*}{$\begin{array}{l}\text { Parâmetros de } \\
\text { Relevo }\end{array}$} & Altitude máxima & $\mathrm{m}$ & 85 \\
\hline & Altitude média & $\mathrm{m}$ & 52,5 \\
\hline & Altitude mínima & $\mathrm{m}$ & 20 \\
\hline & Declividade máxima & $\%$ & 28,06 \\
\hline & Declividade mínima & $\%$ & 0 \\
\hline & Declividade média & $\%$ & 3,11 \\
\hline & Amplitude altimétrica $(\mathrm{Hm})$ & $\mathrm{m}$ & 65 \\
\hline & Relação de relevo (Rr) & $\mathrm{m} / \mathrm{Km}$ & 1,18 \\
\hline & Índice de sinuosidade (Is) & Adimensional & 1,15 \\
\hline & Índice de rugosidade (Ir) & Adimensional & 22,75 \\
\hline & Textura topográfica (Tt) & Adimensional & 5,34 \\
\hline & Fator topográfico $(\mathrm{Ft})$ & Adimensional & 0,004 \\
\hline \multirow{8}{*}{$\begin{array}{c}\text { Parâmetros da } \\
\text { Rede de } \\
\text { Drenagem }\end{array}$} & Comprimento do rio principal (L) & $\mathrm{Km}$ & 63,62 \\
\hline & $\begin{array}{c}\text { Comprimento total da drenagem } \\
\text { (Lt) }\end{array}$ & $\mathrm{Km}$ & 369,72 \\
\hline & Densidade de drenagem (Dd) & $\mathrm{Km} / \mathrm{Km}^{2}$ & 0,35 \\
\hline & Densidade hidrográfica (Dh) & Curso/ Km² & 0,118 \\
\hline & Densidade de confluência (Dc) & Adimensional & 0,06 \\
\hline & Relação de bifurcação (Rb) & Adimensional & 4,1 \\
\hline & $\begin{array}{l}\text { Coeficiente de torrencialidade } \\
(\mathrm{Ct})\end{array}$ & Adimensional & 0,041 \\
\hline & Ordem da bacia & Adimensional & $4^{\circ}$ \\
\hline
\end{tabular}


Para fins de organização dos resultados alcançados, as discussões foram agrupadas em parâmetros Geométricos, de Relevo e de Drenagem, muito embora, em algumas situações, houve a necessidade de correlacionar fatores de diferentes classes de parâmetros buscando elucidar avaliações morfométricas mais complexas da bacia hidrográfica em estudo.

\section{Parâmetros Geométricos}

Considerando os valores alcançados para os parâmetros morfométricos como Área de drenagem, Perímetro e Comprimento do eixo, verificou-se que a bacia em questão é considerada de grande porte, pois segundo classificação de GADELHA (2011), o valor do parâmetro Área de drenagem é muito superior a 26 $\mathrm{km}^{2}$, o que já a classificaria como bacia de elevado porte.

Para se alcançar uma análise mais verossimilhante das características geométricas encontradas na área da bacia e de sua suscetibilidade a enchentes, devem ser avaliados conjuntamente os parâmetros de Coeficiente de compacidade, Fator de Forma, e Índice de circularidade. A análise conjunta destes parâmetros demonstrou que bacia apresentou baixa suscetibilidade a enchentes, comprovado tanto pelo valor do Coeficiente de compacidade, superior a 1,5, quanto pelo Fator de forma, onde o valor foi menor que 0,5 , conforme as classes propostas por SILVA \& MELLO (2013). Esse fato deve-se a forma da bacia hidrográfica estudada ser mais alongada que circular, evidência esta obtida através do Índice de circularidade, onde valores menores que 0,51 demonstram a tendência da bacia em ser alongada (BORSATO \& MARTONI, 2004).

Apesar dos valores do Kc e do Ff encontrados na bacia serem indicativos que a mesma possui forma alongada, como evidenciado na Figura 1, cabe lembrar que o número calculado independe da área considerada, e sim apenas da forma da bacia. Deve-se notar que o Kc se traduz pela relação entre o perímetro da bacia e o perímetro de uma circunferência de um círculo de área igual à da bacia. Para Cardoso et al. (2006), o parâmetro Kc associado à análise de outros índices pode mensurar a susceptibilidade a enchentes depende da proximidade do valor obtido da unidade, isto é, quanto mais próximo de 1 , maior será o risco de ocorrências de enchentes.

Foram observados valores semelhantes dos parâmetros Kc e Ff por ROMANOVSKI (2001), na bacia hidrográfica da Rua Nova, em Viçosa, MG. Este autor encontrou valores de 1,402 para o coeficiente de compacidade e 0,5669 para o fator de forma, indicando que a vazão máxima de enchente seria menor do que ocorreria caso a bacia tivesse a forma de uma circunferência. Tal forma geométrica apresenta eficiência na produção da vazão máxima, o que, em casos de chuva convectiva associada com a densa rede de drenagem, poderia provocar enchentes.

TONELLO et al., (2006), descreve que em bacias de forma circular, há maiores possibilidades de que chuvas intensas ocorrerem simultaneamente em toda a sua extensão da mesma, concentrando grande volume de água no tributário principal. Entretanto, como o valor de Índice de Circularidade encontrado na área de estudo é de 0,27, a bacia apresenta assim um valor menor que 0,51 (limiar de bacias circulares), implicando que a bacia tende a ser alongada, consequentemente favorecendo o processo de escoamento fluvial. 


\section{Parâmetros de Relevo}

Em se tratando de parâmetros de relevo, a altitude é um fator de muita importância, pois indica as variações topográficas da bacia. Neste trabalho observou-se uma Amplitude altimétrica de $65 \mathrm{~m}$, caracterizada por pequenas variações de altitude, sendo a Altitude Máxima de $85 \mathrm{~m}$ nas áreas de nascente e a Altitude Mínima de $20 \mathrm{~m}$ na foz do rio, ficando a Altitude Média em $52,5 \mathrm{~m}$ sendo que as maiores elevações foram encontradas nas bordas da bacia, mais especificamente na região extremo Sul (Figura 2). Segundo TONELLO et al., (2006), a altitude média influencia diretamente na quantidade de radiação que a bacia recebe e, consequentemente, a evapotranspiração, temperatura e precipitação.

Estes valores se aproximam dos encontrados por JÚNIOR (2013), na bacia hidrográfica da Estrada Nova - Belém, que mesmo se tratando de uma bacia relativamente menor que a do Peixe-Boi, apresentou os mesmos fatores climáticos e padrão altimétrico relativamente plano, característicos da região nordeste do estado do Pará.

Os resultados de altimetria encontrados são compatíveis e sustentados por FURTADO \& PONTE (2013), que em seu trabalho utilizando dados do Projeto RADAM Brasil, e, aliado ao mapa de Geomorfologia do Estado do Pará puderam confeccionar o mapa das unidades de relevo do Estado do Pará. Neste produto foi possível observar a compatibilidade altimétricas dos dados obtidos na bacia do rio Peixe-Boi com os dados expressos da região Bragantina produzidos no Laboratório de Análise da Informação Geográfica LAIG/UFPA.

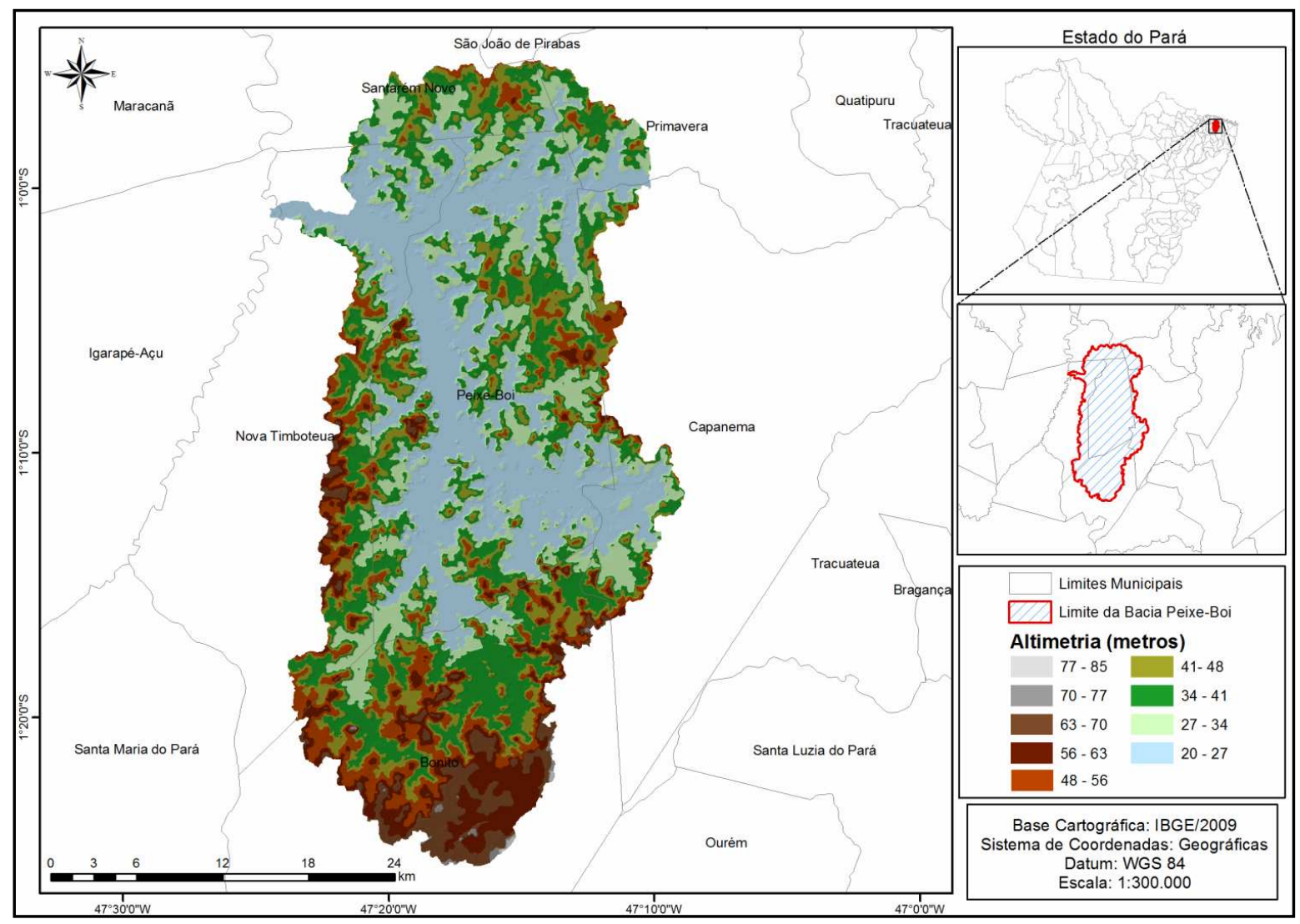

FIGURA 2: Mapa altimétrico da bacia hidrográfica do rio Peixe-Boi. 
No caso de altitudes elevadas, a temperatura é baixa e apenas uma pequena quantidade de energia é utilizada para evaporar a água. Em altitudes baixas, quase toda a energia absorvida é usada para evaporar a água. Constata-se, também, que altitudes elevadas tendem a receber maior quantidade de precipitação, além da perda de água ser menor. Nessas regiões, a precipitação normalmente excede a evapotranspiração, ocasionando, dessa forma, um suprimento de água que mantém o abastecimento regular dos aquíferos responsáveis pelas nascentes dos cursos d’água (CASTRO \& LOPES, 2001).

O resultado obtido para a Altitude Média da bacia sugere um relevo quase plano, não apresentando variação significativa ou perceptível. Devido sua grande extensão e a baixa variação altimétrica da bacia, é enquadrada como de escoamento lento, favorecendo a infiltração e a evaporação. Nota-se que mais de $65 \%$ da área da bacia se apresenta nas classes altimétricas mais baixas $(<41 \mathrm{~m})$, e menos de $0,5 \%$ nas regiões mais elevadas $(>70 \mathrm{~m})$, como apresentado na Tabela 2.

TABELA 2: Quantificação espacial e distribuição percentual da bacia hidrográfica do rio Peixe-Boi, por classe de Altimetria.

\begin{tabular}{c|r|c}
\hline $\begin{array}{c}\text { Classes } \\
\text { Altimétricas }(\mathbf{m})\end{array}$ & $\begin{array}{c}\text { Área } \\
\left(\mathbf{k m}^{2}\right)\end{array}$ & $\%$ \\
\hline $20-27$ & 318,38 & 30,79 \\
\hline $27-34$ & 195,84 & 18,94 \\
\hline $34-41$ & 167,44 & 16,19 \\
\hline $41-48$ & 142,62 & 13,79 \\
\hline $48-56$ & 104,99 & 10,15 \\
\hline $56-63$ & 68,01 & 6,57 \\
\hline $63-70$ & 32,38 & 3,13 \\
\hline $70-77$ & 3,56 & 0,34 \\
\hline $77-85$ & 0,71 & 0,07 \\
\hline TOTAL & $\mathbf{1 0 3 4}$ & $\mathbf{1 0 0}$ \\
\hline
\end{tabular}

Um dos mais importantes parâmetros de relevo é representado pela declividade do terreno, que é expressa como sendo a variação de altitude entre dois pontos do terreno, em relação à distância que os separa. As classes de declividade geradas neste tema foram reclassificadas em cinco intervalos distintos adaptados de CREPANI et al., (2001), como apresentado na Figura 3. O mapa trata-se de uma reclassificação da declividade em quatro classes, ao passo que a Tabela 3 apresenta as informações quantitativas associadas às classes de relevo. Observa-se que a grande parte da área da bacia corresponde às classes de relevo Muito baixo e Baixo ( $<6 \%$ de declividade), representando $84,38 \%$ da área total da bacia. $A$ Declividade Máxima foi de $28,06 \%$, a Declividade Mínima foi igual a zero e a Declividade Média encontrada para a bacia hidrográfica foi de $3,11 \%$, sendo este valor condizente com o relevo pouco ondulado da região. 


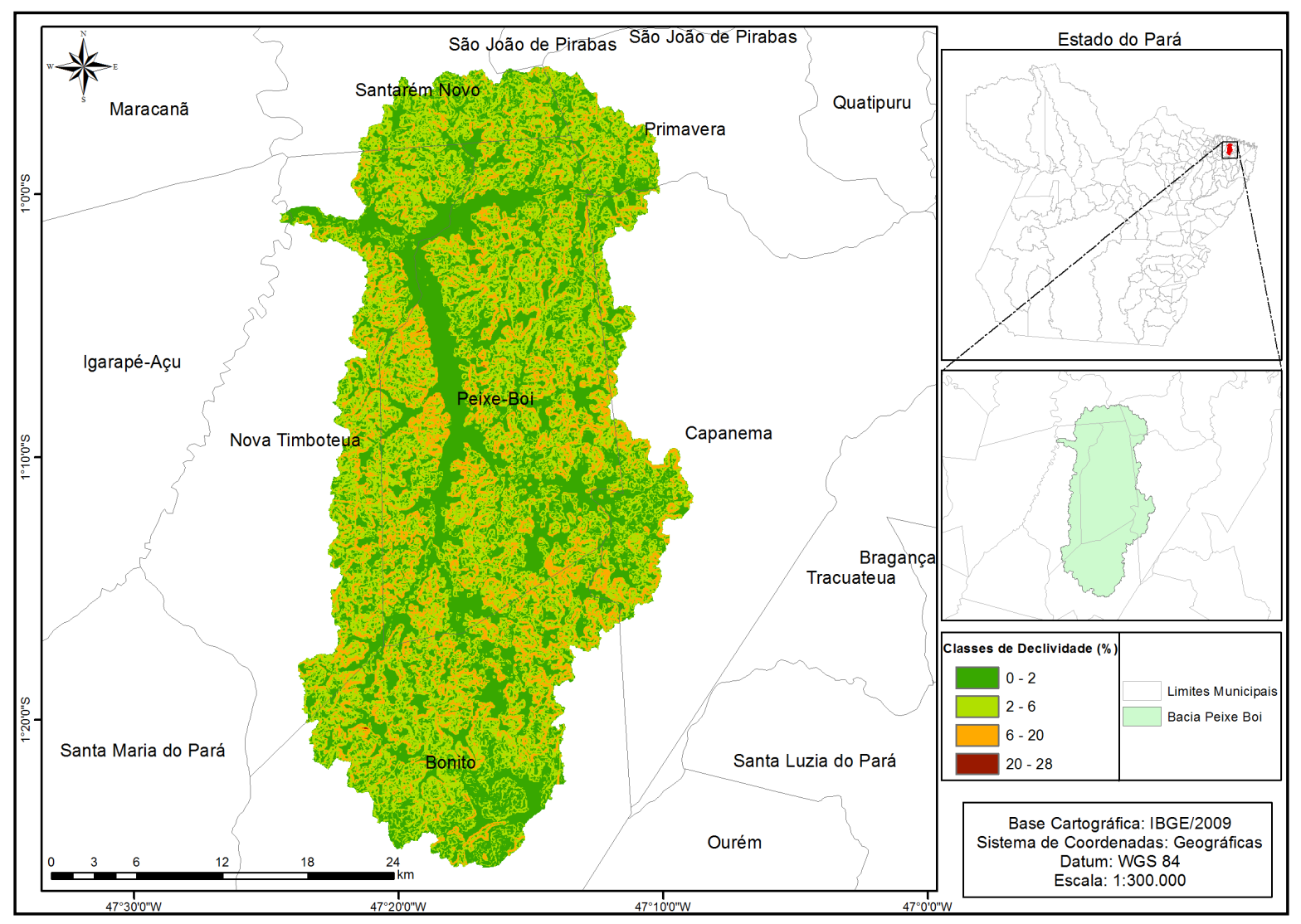

FIGURA 3: Mapa de declividade da bacia hidrográfica do rio Peixe-Boi.

TABELA 3: Quantificação de áreas para cada classe de relevo na bacia \begin{tabular}{l|l|l|l|l} 
Classes Morfométricas & Declividade (\%) & Área $\left(\mathbf{k m}^{2}\right)$ & $\%$ & $\mathrm{i}$ \\
& & &
\end{tabular} ográfica do rio Peixe-Boi.

\begin{tabular}{c|c|c|c} 
Muito Baixa & $<2$ & 421,35 & 40,74 \\
\hline Baixa & $2-6$ & 451,30 & 43,64 \\
\hline Média & $6-20$ & 161,26 & 15,59 \\
\hline Alta & $20-50$ & 0,09 & 0,01 \\
\hline Muito Alta & $>50$ & 0 & 0 \\
\hline TOTAL & - & 1034 & 100 \\
\hline
\end{tabular}


É possível observar na Tabela 3 que é praticamente irrisório o quantitativo de áreas com relevo acima de $20 \%$ de declividade, perfazendo uma área de menos de $0,1 \mathrm{~km}^{2}$. Novamente, esses dados se aproximam em muito com os valores obtidos por JÚNIOR (2013), na bacia hidrográfica da Estrada Nova - Belém, que obteve $89,4 \%$ da área da bacia em áreas de declividade muito baixa e baixa, o que remete ao padrão normalmente plano das áreas localizadas ao nordeste do estado do Pará.

A declividade média da bacia ficou em $3,11 \%$ que é o valor mais representativo pra grande parte da Bacia. No que tange a declividade média sabe-se que ela expressa uma relação direta e complexa com os fatores infiltração, escoamento superficial, umidade do solo e a contribuição de água subterrânea ao escoamento do curso d'água. Como o relevo predominante é plano, este é um dos fatores mais importantes que controla o tempo do escoamento superficial e da concentração da chuva, tendo uma importância direta em relação à magnitude da enchente. Entende-se que quanto maior a declividade maior a variação das vazões instantâneas (TONELLO et al., 2006).

Para SANTOS \& SOBREIRA (2008), a baixa velocidade da água devido à declividade do terreno pode agir como agravante na ocorrência de enchentes da bacia hidrográfica. Entretanto, o escoamento rápido, também implica na aceleração do processo de retirada do solo, ocasionado pela erosão. Dessa forma, verifica-se que é imprescindível o equilíbrio entre infiltração e escoamento superficial, bem como a preservação da vegetação, para que as áreas não impermeabilizadas tornem-se passíveis dos processos erosivos.

Quanto ao fator escoamento superficial, em relação à inclinação do relevo, torna-se importante considerar que a declividade atua como controladora de boa parte da velocidade do escoamento interferindo no tempo que a água da chuva leva para chegar até os leitos das drenagens (SALA \& GASPARETTO, 2010).

No que tange ao Fator Topográfico (Ft), sabe-se que seu objetivo é analisar a capacidade de escoamento de uma bacia hidrográfica por meio da densidade hidrográfica, índice de circularidade e a razão de relevo relativo. O valor encontrado desse fator para este estudo foi extremamente baixo 0,004, sendo assim a bacia apresenta baixíssima capacidade de enchente e com boa capacidade de escoamento. O valor obtido foi favorecido devido aos baixos valores do índice de circularidade e de relação de relevo.

Compreende-se que além da constituição geológica do terreno e da cobertura vegetal do mesmo, a declividade é o fator topográfico mais relevante no condicionamento da gênese e evolução do processo erosivo, haja vista que quanto maior for a inclinação da encosta, mais acentuado será o processo de escoamento superficial (TONELLO et al., 2006).

O resultado para o Índice de sinuosidade (Is) de 1,15 indicou para os rios da bacia, principalmente para o rio principal, uma tendência a serem pouco sinuosos como pode ser observado na Figura 1. Valores próximos a 1,0 indicam que o canal tende a ser retilíneo. Já os valores superiores a 2,0 sugerem canais tortuosos e os valores intermediários indicam formas transicionais, regulares e irregulares, com pequena capacidade de acúmulo de sedimentos (TEODORO et al., 2007). O rio Peixe-Boi praticamente não apresenta trechos com significativo acúmulo de sedimentos e/ou processos erosivos devido à sinuosidade. Por outro lado, a intensificação da ação antrópica e da ocupação desordenada das margens dos rios, principalmente no curso inferior médio do rio principal, próximo à Capanema e Peixe-Boi, tem promovido perturbações consideráveis em alguns pontos críticos. 
O baixo valor referente ao parâmetro Relação de relevo $(\mathbf{R r})$ de $1,18 \mathrm{~m} / \mathrm{Km}$ indica um escoamento bastante lento nos canais da Bacia. Este índice compara a altimetria das regiões, sabendo-se que quanto maiores seus valores, mais acidentado é o relevo predominante na região, refletindo a relação infiltração/deflúvio, o que demonstra uma relação próxima com a densidade de drenagem (ROSSI \& PFEIFER, 1999). Dessa maneira pode se entender que o relevo é predominantemente baixo indicando uma boa estabilidade do relevo na área de estudo. Para TEODORO et al., (2007), o baixo valor de Relação de relevo indica vertentes curtas e confirma a baixa probabilidade natural de ocorrerem cheias relâmpagos na região da bacia com esta característica.

A informação de Relação de relevo alcançada para a bacia do rio Peixe-Boi é confirmada por FURTADO \& PONTE (2013), no seu trabalho de mapeamento de unidades de relevo do estado do Pará, onde a área referente à bacia está classificada como sendo de Planaltos Rebaixados da Amazônia, que são áreas de escoamento lento, onde a altimetria é menor e relativamente homogênea, indicando uma estabilidade do relevo.

$\mathrm{O}$ baixo valor do Índice de rugosidade (Ir) de 22,75, juntamente com 0 resultado do índice de Relação de relevo reforça a ideia de baixa possibilidade do evento de cheias exposta anteriormente. O valor desse índice foi pouco representativo e define menor risco de degradação da bacia, uma vez que apresenta pouca variação em seu relevo, com poucos desníveis entre a cabeceira e a seção de referência associados à densa rede de drenagem.

Isoladamente o índice de rugosidade não expressa precisamente as informações necessárias para se caracterizar o relevo, sendo necessário uma avaliação combinada com outros indicadores como a Relação de relevo e Fator topográfico para se chegar a um denominador mais eficaz (ROSSI \& PFEIFER, 1999).

A Textura topográfica (Tt), indica o grau erosivo da área, sendo para FREITAS (1952) classificado de acordo com os índices de valores de drenagem: abaixo de 4,0 como de textura grosseira, entre 4,0 e 10,0 como de textura média e acima de 10,0 como sendo de textura fina. Para o valor verificado $(5,34)$, a textura topográfica pode ser classificada como sendo textura média, indicando a intensidade de entalhamento topográfico realizado pelos rios.

CHRISTOFOLETTI (1980) considera a textura topográfica como indicadora do estágio erosivo de uma determinada região. Assim, valores de textura topográfica estão diretamente relacionados aos de densidade de drenagem. Por sua vez, os valores de coeficiente de manutenção e da extensão do percurso superficial estão inversamente relacionados aos da densidade de drenagem.

BARBOSA \& CARVALHO (2009), em estudos na bacia do Arroio do Padre PR obtiveram valores dos parâmetros Textura topográfica e Índice de rugosidade, 4,35 e 20,06 respectivamente e, semelhante a esse estudo, também confirmando tal bacia como sendo de textura média, com pouca variação em seu relevo e baixo risco à inundação.

É importante observar que além do grau de entalhamento, a Textura de topografia também representa o grau de dissecação da superfície terrestre, por se tratar de um indicador do estágio erosivo da região. 


\section{Parâmetros da Rede de Drenagem}

Para a realidade da área de estudo, os valores dos parâmetros Comprimento do Rio Principal (L) e Comprimento total da rede de drenagem (Lt) foram de $63,62 \mathrm{~km}$ e $369,72 \mathrm{Km}$, respectivamente. O comprimento do rio principal é um índice que compreende a distância que se estende ao longo do canal fluvial desde a desembocadura até uma determinada nascente no outro extremo. O critério utilizado para a determinação do comprimento do rio Peixe-Boi foi o estabelecido por HORTON (1985), no qual o canal de ordem mais elevada corresponde ao rio principal, que neste caso é um canal de $4^{\mathrm{a}}$ ordem (Figura 4).

Observa-se que os processos erosivos tendem a ser mais severos na região mais alta da bacia hidrográfica, que é formada basicamente pelos rios de primeira ordem, porém, pequenos tributários também possuem ação erosiva devido à alta energia por desenvolverem-se em áreas com as maiores declividades da bacia hidrográfica como visto na figura 4.

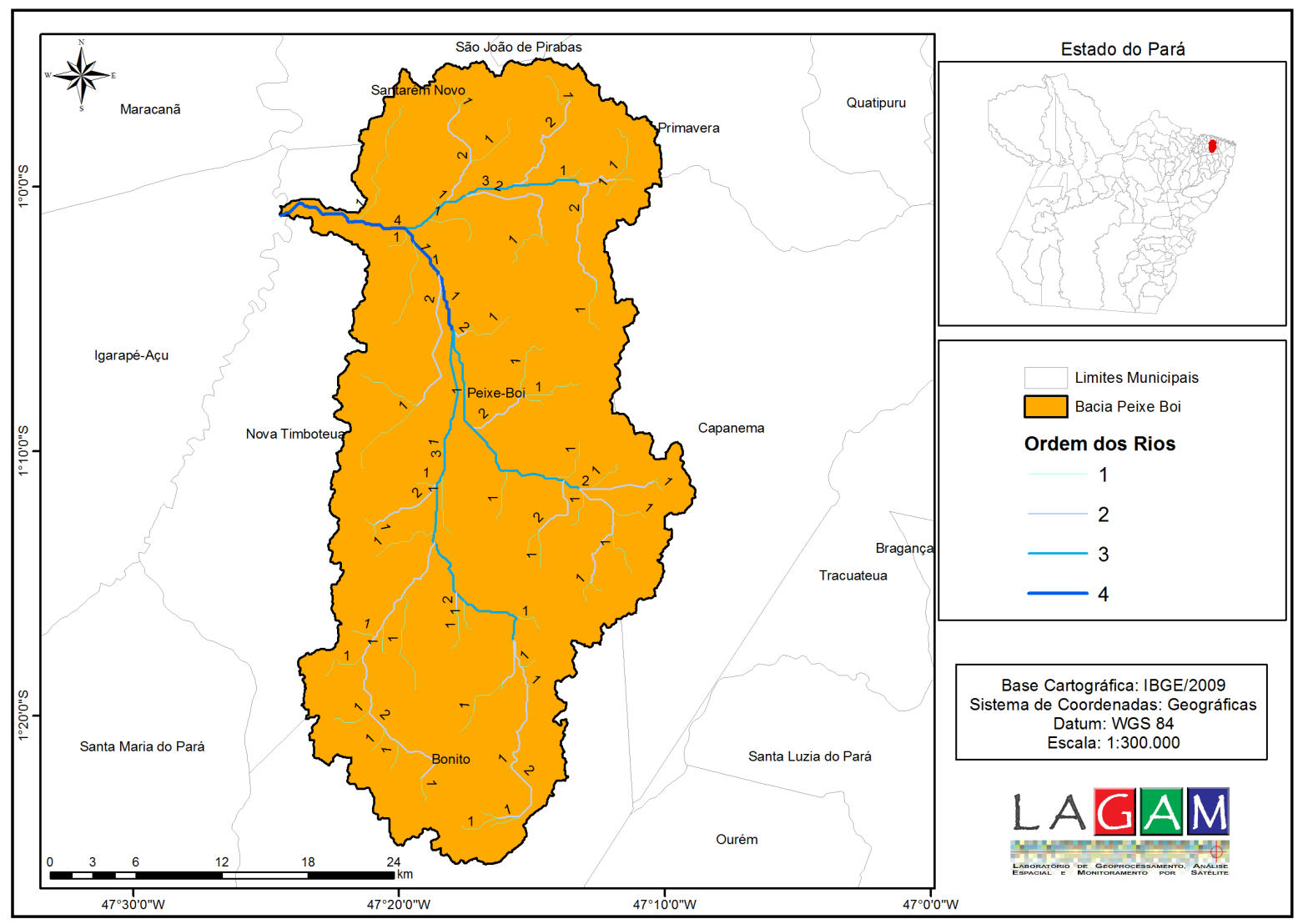

FIGURA 4: Mapa da Hierarquia fluvial da bacia hidrográfica do rio Peixe-Boi.

A partir do ordenamento dos canais apresentado na Figura 4, verificou-se que a área de estudo apresentou grau de ramificação de $4^{\mathrm{a}}$ Ordem, segundo a hierarquia proposta por STRAHLER (1952), que propõe uma ordenação que elimina o conceito de que o rio principal deve ter o mesmo número de ordem em toda a extensão e a necessidade de se refazer a numeração a cada confluência. Este ordenamento indica que a bacia do rio Peixe-Boi mostra-se pouco ramificada, pois a ordem inferior ou igual a 4 é comum em pequenas bacias hidrográficas e reflete os efeitos diretos 
do uso da terra e fragilidade dos recursos hídricos. Sabe-se que, quanto mais ramificada for a rede, mais eficiente será o sistema de drenagem.

Pela análise da Tabela 4, foi possível concluir que mais de $96 \%$ da drenagem da bacia é constituída por rios de $1^{\underline{a}}$ e $2^{\underline{a}}$ ordens, sendo os comprimentos médios dos rios para essas ordens estão classificados como pequenos, assim como o número de rios dessas ordens estão abaixo do estipulado por ALCÂNTARA \& AMORIM (2005), para uma bacia desse porte. Quanto mais seguimentos apresentar um rio, mais diversidade de habitat e maior disponibilidade de nichos ecológicos sustentarão o ambiente (THORP et al., 2010).

TABELA 4: Quantificação percentual do número, comprimento e bifurcação de rios da bacia do rio Peixe-Boi conforme sua ordem hierárquica.

\begin{tabular}{c|c|c|c|c|c}
\hline $\begin{array}{c}\text { Ordem dos } \\
\text { Rios }\end{array}$ & $\begin{array}{c}N^{\circ} \text { de } \\
\text { Rios }\end{array}$ & $\begin{array}{c}\text { Extensão } \\
(\text { Km) }\end{array}$ & $\begin{array}{c}\text { Comprimento } \\
\text { Médio dos Rios }\end{array}$ & $\begin{array}{c}\text { Percentu } \\
\text { al }\end{array}$ & $\begin{array}{c}\text { Relação } \\
\text { de } \\
\text { Bifurcaçã } \\
0\end{array}$ \\
\hline $1^{\circ}$ & 50 & 174,03 & 2,52 & $76 \%$ & - \\
\hline $2^{\circ}$ & 13 & 120,35 & 3,43 & $20 \%$ & 3,84 \\
\hline $3^{\circ}$ & 2 & 56,93 & 28,46 & $3 \%$ & 6,50 \\
\hline $4^{\circ}$ & 1 & 18,39 & 18,39 & $1 \%$ & 2,00 \\
\hline TOTAL & 66 & $\mathbf{3 6 9 , 7 2}$ & - & $100 \%$ & - \\
\hline
\end{tabular}

No que tange aos resultados encontrados para a Relação de bifurcação, 3,84 observou-se para a relação entre o número de canais de segunda ordem, para os canais de terceira ordem o resultado foi 6,5 , e a relação de bifurcação entre os canais de quarta ordem foi de 2 . Todos os resultados foram superiores ou iguais a dois $(\mathrm{Rb} \leq 2)$, como estabelecido por STRAHLER (1952). Este índice indica o grau de dissecação da bacia hidrográfica, quanto maior for o valor do índice de bifurcação maior será o grau de dissecação, valores geralmente abaixo de 2 indicam relevo colinoso.

Segundo SILVA \& LIMA (2000), o valor desse parâmetro é maior para áreas amorreadas, com bacias de drenagem muito dissecadas, a bacias com áreas colinosas, sendo de 3 a 4 para as primeiras e de somente 2 para as últimas.

Um ponto que merece atenção são as maiores altitudes onde a maioria dos canais de primeira ordem são encontrados. Ao todo são contabilizados 50 canais de primeira ordem em toda área da bacia, e a maioria deles (37), localizam-se em áreas com altitude superior a 40m, indicando que o fator morfológico é determinante para a configuração da bacia em questão (Tabela 5). BARBOSA et al., (2011) \& FURRIER et al., (2012) encontraram resultados semelhantes ao descrito acima em bacias hidrográficas com características de relevo semelhantes.

TABELA 5: Quantificação de canais em cada classe de altimetria para a bacia do rio Peixe-Boi.

\begin{tabular}{c|c|c|c|c}
$60-80$ & $1^{\circ}$ Ordem & $2^{\circ}$ Or̃dem & $3^{\circ}$ Or̈dem & $4^{\circ}$ Oŕdem \\
\hline$>80$ & 1 & - & - & - \\
\hline TOTAL & 50 & 13 & 2 & 1 \\
\hline $40-O 0$ & 16 & 2 & 2 & - \\
\hline
\end{tabular}


A Densidade de drenagem de $0,35 \mathrm{Km} / \mathrm{Km}^{2}$ foi considerada muito baixa, segundo a classificação de SILVA \& MELLO (2013), com sistema de drenagem pouco desenvolvido, pois o valor encontrado foi menor que $0,5 \mathrm{~km} / \mathrm{km}^{2}$. Este padrão indica que a bacia hidrográfica apresenta baixa relação entre o comprimento de rios e a área ocupada pela mesma (Tabela 4), possivelmente devido a um eficiente escoamento de fluxo de água e boa infiltração para o lençol freático, apresentando menor propensão a inundações, fato este corroborado pelo valor baixo do Coeficiente de Torrencialidade $(0,041)$.

A classificação dos canais fluviais através do índice densidade de drenagem proposta por SILVA \& MELLO (2013), aponta que a densidade de drenagem pode variar de $0,5 \mathrm{Km} / \mathrm{Km}^{2}$ (bacias mal drenadas devido a elevada permeabilidade ou precipitação escassa) a $3,5 \mathrm{Km} / \mathrm{Km}^{2}$ (bacias excepcionalmente bem drenadas ocorrendo em áreas com elevada precipitação ou muito impermeáveis).

A análise do coeficiente de torrencialidade precisa estar diretamente correlacionada à precipitação pluviométrica média da área estudada. No caso da bacia do rio Peixe-Boi, a média pluviométrica anual da região está em torno de $2.200 \mathrm{~mm}$, sendo considerada elevada. Neste caso temos um coeficiente de torrencialidade baixo e um índice de pluviosidade elevado, assim, os fatores decisivos para caracterizar um risco de enchentes seriam conjuntamente a densidade de drenagem, o fator topográfico e a permeabilidade do solo.

RODRIGUES \& ADAMI (2005), afirmam que com o uso dos dados de Densidade de drenagem e Coeficiente de Torrencialidade é possível separar áreas mais ou menos aptas à recepção de infra-estrutura viária, por exemplo. Esses dados também podem ser um valioso auxílio para interpretações sobre morfogênese e morfodinâmica baseadas em inferências sobre diferenças de permeabilidade ou de diferença sobre a profundidade dos materiais permeáveis.

Outro parâmetro que demostra a baixa susceptibilidade da bacia em sofrer inundações pode ser verificado pela Densidade Hidrográfica de $0,118 \mathrm{Curso} / \mathrm{Km}^{2}$, mostrando que existe aproximadamente um rio para cada dez quilômetros quadrados da bacia. Isto indica um ambiente deficitário quanto a drenagem e pouco favorável à geração de novos cursos fluviais, segundo apresentado por CASTRO \& CARVALHO (2009), em semelhante estudo. Nota-se, também, que dentro de dez quilômetros quadrados a probabilidade de encontrar pelo menos uma união de dois cursos d'água ou mais é muito baixa, fato este encontrado a partir do valor de Densidade de Confluência de 0,06, bem longe do valor unitário (1).

É importante observar a correlação inversa existente entre a Densidade de drenagem e a Densidade hidrográfica, visto que, quanto mais canais existirem, menos extensos eles serão. A densidade hidrográfica é um índice de grande relevância, pois indica se a bacia é bem servida de boa rede de canais ou não. Representa também o comportamento hidrográfico das bacias, uma vez que, em bacias com alta densidade hidrográfica, pode-se inferir uma maior capacidade de gerar canais, independentemente de suas extensões. Uma bacia é considerada bem drenada quando tem um canal por $\mathrm{km}^{2}$ (BARBOSA \& CARVALHO, 2009).

\section{CONCLUSÕES}

Os resultados obtidos por este trabalho nos permitem concluir que as geotecnologias apresentam ferramentas de fundamental importância para se extrair informações espaciais do meio físico para a caracterização e avaliação ambiental de 
bacias hidrográficas. Os produtos de sensoriamento remoto e as ferramentas de geoprocessamento mostraram-se eficientes na modelagem, identificação, análise, interpretação e quantificação de variáveis do relevo e drenagem da bacia hidrográfica do rio Peixe-Boi.

A bacia hidrográfica do rio Peixe-Boi possui a forma alongada, evidenciando um menor risco de cheias em condições normais de pluviosidade anual. A bacia apresenta o relevo relativamente plano em sua maior área, sendo caracteriza como pouco ondulado, uma amplitude altimétrica relativamente baixa, e drenagem caracteriza como baixa, com sistema de drenagem pouco desenvolvido e precipitação pluviométrica média anual elevada. Esses parâmetros têm grande influência sobre o escoamento superficial e, consequentemente, sobre o processo de erosão e inundação e atestam que escoamento da água na bacia em questão é lento.

A drenagem da bacia apresenta um padrão pouco sinuoso formado por reduzidos cursos d'água e tributários, que são de grande relevância para a população local que utiliza da água para sua subsistência, com a utilização das margens para o plantio de hortaliças, o que contribui para o assoreamento dos canais. Nessa perspectiva, faz-se necessário estudo sobre o uso e cobertura do solo na área da bacia, assim como estudos sedimentológicos no rio principal, objetivando analisar a relação da ocupação das suas margens e do despejo de resíduos sólidos com casos de eventuais enchentes e poluição hídrica.

É importante destacar que a bacia do rio Peixe-Boi sofre com o avanço da ocupação desordenada e sem planejamento, atrelado a falta de saneamento básico, uma vez que a população lança no rio, resíduos sólidos e efluentes domésticos sem tratamento, através de ligações de esgoto clandestinas.

Considerando o contexto em que se encontra esta bacia, os resultados alcançados nesse trabalho podem abrir novas perspectivas quanto a medidas de planejamento estratégico e gestão dos recursos hídricos da área em questão. De posse dos dados morfométricos e dos diversos produtos gerados por este trabalho, apresenta-se potencial perspectivas de realizar diversos outros estudos voltados à conservação dos recursos hídricos e de políticas públicas voltadas para a bacia hidrográfica a em questão.

\section{AGRADECIMENTOS}

Os autores agradecem a Universidade Federal Rural da Amazônia e ao seu renomado Instituto Ciberespacial - ICIBE pela oportunidade de desenvolver os estudos, assim como ao Laboratório de Geoprocessamento, Análise Espacial e Monitoramento por Satélite - LAGAM e seus profissionais pelo apoio logístico, técnico e científico.

\section{REFERÊNCIAS}

ALCÂNTARA, E. H.; AMORIM, A. de J. Análise morfométrica de uma bacia hidrográfica costeira: um estudo e caso. Caminhos da Geografia, Uberlândia, v.14, n. 7, p 70-77, 2005. 
BARBOSA, M. E. F.; FURRIER, M. Análise de bacia hidrográfica como subsídio para detecção de Neotectônica: estudo da bacia hidrográfica do rio Guruji, Litoral Sul do estado da Paraíba. Cadernos de Geociências, v. 8, n. 1, p. 10-18, 2011.

BORSATO, F.H.; MARTONI, A.M. Estudo da Fisiografia das Bacias Hidrográficas Urbanas no Município de Maringá, Estado do Paraná. Acta Scientiarum. Human and Social Sciences. v.26, nำ, p.273-285, 2004.

BARBOSA, Y. B.; CARVALHO, S. M. Análise morfométrica da bacia do Arroio do Padre, Ponta Grossa - PR. Caminhos de Geografia Uberlândia v. 10, n. 30 p. 160 - 173 Página 160, Mar/ 2009.

CASTRO, S.B.; CARVALHO, T.M. Análise morfométrica e geomorfologia da bacia hidrográfica do rio Turvo-GO, através de técnicas de sensoriamento remoto e geoprocessamento. Scientia plena, v.5, n.2. 2009

CASTRO, P.; LOPES, J.D.S. Recuperação e Conservação de nascentes. Viçosa: CPT, 84p. 2001.

CARDOSO, C. A. PONTE, V. C. SANTOS, S. Caracterização morfométrica da bacia hidrográfica do rio Debossan, Nova Friburgo, RJ. Revista Árvore, v. 30, n. 2, p. 241248, 2006.

CREPANI, E. M.; MEDEIROS, J. S. de; HERNANDEZ FILHO, P.; FLORENZANO, T. G.; DUARTE, V.; BARBOSA, C. C. F. Sensoriamento remoto e geoprocessamento aplicados ao Zoneamento Ecológico-Econômico e ao ordenamento territorial. São José dos Campos: 124 p. INPE, 2001.

CHRISTOFOLLETI, A. Geomorfologia, 280p, 1980.

CRUZ, F. M.; CAVALCANTE, L. M.; OLIVEIRA, W. P.; SANTOS, V. J. C.; SANTOS, S. A. Diagnóstico ambiental da bacia do rio Peixe-Boi como subsídio à construção de um plano de manejo de bacia hidrográfica. In: XVIII Simpósio Brasileiro de Recursos Hídricos, Campo Grande - MS, Anais, ABRH, 183-198 p. 2009.

DIAS, L.S.O.; ROCHA, G.A.; BARROS, E.U.A.; MAIA, P.H.P. Utilização do radar interferométrico para delimitação automática de bacias hidrográficas. Bahia Análise \& Dados, Salvador, v. 4, n.2, p.265-271, 2004.

FERRARI, J. L.; SILVA, S. F.; SANTOS, A. R.; GARCIA, R. F. Análise morfométrica da sub-bacia hidrográfica do córrego Horizonte Alegre, ES. Revista Brasileira de Ciências Agrárias, v. 8, n. 2, p. 181-188, 2013.

FREITAS, R. O. Textura da drenagem e sua aplicação geomorfológica. Boletim Paulista de Geografia, n. 11, p. 53-57, jul. 1952.

FURTADO, A. M. M., PONTE, F. C. MAPEAMENTO DE UNIDADES DE RELEVO DO ESTADO DO PARÁ, Revista GeoAmazônia, Belém, v. 02, n. 2, p. 56 - 67, jul./dez. 2013. 
FURRIER, M; BARBOSA, T. S. Avaliação morfológica e morfométrica da bacia hidrográfica do rio Marés - $P B$, para verificação de influência neotectônica. Cadernos de Geociências, v. 9, n. 2, p. 215-228, 2012.

GADELHA, C. T.: Utilização de Geotecnologias para Caracterização Morfométrica da Bacia Hidrográfica do Açude de Sumé-PB. Instituto Federal de Educação, Ciência e Tecnologia da Paraíba - IFET-PB. João Pessoa: 2011.

HORTON, R. E. Erosional development of streams and their drainage basins. Hydrophysical approach to quantitative morphology. Geol Soc Am Bull. 56:275-370 (1945) Informe Agropecuário, Belo Horizonte. v. 11, n. 128. p. 55-69, ago. 1985.

IBGE. Banco de Dados. 2008. Disponível em: http://www.ibge.gov.br/home/presidencia/noticias/noticia_visualiza.php?id_noticia=12 46\&id_pagina=1. Acesso em: 24 mai/2014.

IBGE, Instituto Brasileiro de Geografia e Estatística, diretoria de geociências, mapastematicos_pedologia/unidades_federação/pa_pedologia, 2012.

INSTITUTO NACIONAL DE PESQUISAS ESPACIAIS/ DIVISÃO DE PROCESSAMENTO DE IMAGENS (INPE/DPI). Topodata: banco de dados morfométricos do Brasil. Disponível em http://www.dsr.inpe.br/topodata/index.php. Acessado em Dezembro. 2014.

JUNIOR, A. C. R. A. Fatores de risco a inundação na bacia hidrográfica da Estrada Nova Belém - PA, Pa, Brasil. Geografia (Londrina), v.22, n.2. p. 57-78, maio/ago. 2013.

LANG, S.; BLASCHKE,T. Analise da Paisagem com SIG. Ed. Oficina De Textos. $1^{\underline{a}}$ Edição - p. 424 - 431, 2009.

LIRA, E. M.; NASCIMENTO, F. I. C.; ALMEIDA, G. O.: Análise Morfométrica da Bacia Hidrográfica do Igarapé Amaro, Acre-Brasil. Revista Geonorte, Edição Especial, V.3, N.4, p. 606-616, 2012.

MACHADO, R. A. S.; LOBÃO, J. S. B.; VALE, R. M. C.; SOUZA, A. P. M. J. Análise morfométrica de bacias hidrográficas como suporte a definição e elaboração de indicadores para a gestão ambiental a partir do uso de geotecnologias. In: Anais XV Simpósio Brasileiro de Sensoriamento Remoto -SBSR, Curitiba, PR, Brasil, 30 de abril a 05 de maio de 2011, INPE p.1441. 2011

MOSCA, A.A.O. Caracterização hidrológica de duas microbacias visando à identificação de indicadores hidrológicos para o monitoramento ambiental do manejo de florestas plantadas. 2003. 96f. Tese (Doutorado) - Escola Superior de Agricultura Luiz de Queiroz (ESALQ/USP), Piracicaba, SP, 2003.

RODRIGUES, C.; ADAMI, S. Técnicas fundamentais para o estudo de bacias hidrográficas. In: VENTURI, L. A. B. (org.) Praticando geografia: técnicas de campo e laboratório em geografia e análise ambiental. São Paulo: Editora Oficina de Textos. 2005. 
ROMANOVSKI, Z. Morfologia e aspectos hidrológicos para fins de manejo da microbacia da Rua Nova, Viçosa-MG, para fins de manejo. 2001. 99f. Tese (Doutorado) - Universidade Federal de Viçosa, Viçosa, MG, 2001.

ROSSI, M.; PFEIFER, R.M. Remoção de material erodido dos solos de pequenas baciashidrográficas no Parque Estadual da Serra do Mar em Cubatão (SP). Bragantia, Campinas, v. 58, n.1, p.141 - 156, 1999.

SALA, M. G.; GASPARETTO, N. V. L.: Fragilidade Ambiental dos solos em Bacias Hidrográficas de pequena ordem: o caso da Bacia do Ribeirão Raringá-Pr. Bol. Geografia. Maringá, v. 28, n. 2, p. 113-126, 2010.

SANTOS, A. M.; TARGA, M. S.; BATISTA, G. T.; DIAS, N. W. Análise morfométrica das sub-bacias hidrográficas Perdizes e Fojo no município de Campos do Jordão, SP, Brasil. Revista Ambiente \& Água, v. 7, n. 3, p. 195-211, 2012.

SANTOS, C. A.; SOBREIRA, F. G. Análise morfométrica como subsídio ao zoneamento territorial: o caso das bacias do Córrego Carioca, Córrego do Bação e Ribeirão Carioca na região do Alto Rio das Velhas-MG. Revista Escola de Minas (REM), v. 61, n. 1, p. 77-85, 2008.

SCHUMM, S. A. Evolution of drainage systems and slopes in badlands at Perth Amboy. Bull. Geol. Soc. America. 67:597-646, 1956.

SECRETARIA DE ESTADO DE MEIO AMBIENTE-SEMA. Política de Recursos Hídricos do Estado do Pará. Belém, 2012.

STIPP, N. A. F.; CAMPOS, R. A.; CAVIGLIONE, J. H. Análise morfométrica da bacia hidrográfica do rio Taquara - Uma contribuição para o estudo das ciências ambientais. Portal da Cartografia, Londrina, v. 3, n. 1, 2010.

SILVA, A. M.; LIMA, L. C. Caracterização fisiográfica da bacia do rio Peixe-Boi. Brasil. Revista Ambiente \& Água, v. 2, n. 2, p. 151-203, 2000.

SILVA, A.M.; MELLO,C.R. Apostila de Hidrologia. Universidade Federal de Lavras. InSite:www.deg.ufla.br/Irriga\%C3\%A7\%C3\%A3o/Disciplinas/ENG\%20170/hidrologia _eng170.htm. Acesso em: 10 Julho 2013.

STRAHLER, A.N. Hypsometric (area-altitude) - analysis of erosion al topography. Geol. Soc. America Bulletin. 63:1117-1142, 1952.

TEIXEIRA, A.J.A., CRUZ, C.B.M. Classificação de bacias de drenagem com o suporte do sensoriamento remoto e geoprocessamento - o caso da Baía de Guanabara. In: Simpósio Brasileiro de Sensoriamento Remoto, 12, Goiânia, 2005. Anais XII SBSR, p. 2779-2786.2005.

TEODORO, V. L. I; TEIXEIRA, D.; COSTA, D. J. L.; FULLER, B. B. O conceito de bacia hidrográfica e a importância da caracterização morfométrica para 0 entendimento da dinâmica ambiental local. Revista Uniara. n. 20, p. 137-155, 2007. 
TONELLO, K. C.; DIAS, H. C. T.; SOUZA, A. L.; RIBEIRO, C. A. A. S.; LEITE, F. P. Morfometria da bacia hidrográfica da Cachoeira das Pombas Guanhães - MG. Revista Árvore. Viçosa-MG, v. 30, n. 5, p.849-857, 2006.

THORP, J. H.; FLOTEMERSCH, J. E.; DELONG, M. D.; CASPER, A. F.; THOMS, M. C.; BALLANTY, F.; WILLIAMS, Bradley S. Linking ecosystem services, rehabilitation, and river hydrogeomorphology. BioSciense 60: 67-74, 2010

VILELLA, S.M; MATTOS, A. Hidrologia Aplicada. Sao Paulo: McGraw-Hill, 1975. 